\title{
Impact of a telephone helpline for smokers who called during a mass media campaign
}

\author{
Lesley Owen
}

\begin{abstract}
Objective-To evaluate the impact of a telephone helpline (Quitline) with additional support (written information) on callers who use the service during a mass media campaign.
\end{abstract}

Design-Telephone recall surveys of callers to the helpline carried out two months and one year after their initial call.

Setting-Telephone helpline.

Subjects-Callers to the helpline.

Main outcome measures-Smoking behaviour change among callers to the helpline at two months and one year. Results-At one year $22 \%$ (95\% confidence interval (CI) $18.4 \%$ to $25.6 \%$ ) of smokers reported that they had stopped smoking. Assuming that those who refuse to take part in the one year follow up are continuing smokers and a further $20 \%$ of reported successes fail biochemical validation, this yields an adjusted quit rate of $15.6 \%$ (95\% CI $12.7 \%$ to $18.9 \%$ ) at one year. Among ex-smokers, $41 \%$ (95\% CI $34.3 \%$ to $47.7 \%$ ) reported that they were still not smoking at one year. The adjusted figure for ex-smokers at one year is $29 \%$ (95\% CI $23.3 \%$ to $34.8 \%$ ). Of those who resumed smoking $28 \%$ were smoking less than they had been initially. Currently Quitline receives around half a million calls in the course of one year, $93 \%$ of whom are phoning for themselves. This represents $4.2 \%$ of the total population of adults smokers in England.

Conclusion-The Health Education Authority's advertising campaign was extremely successful in generating calls to the helpline. Very large numbers of smokers from diverse backgrounds, including the key groups highlighted in the UK government's recent proposals on tobacco, called the Quitline, which appeared to be very successful in helping these callers to stop smoking. For a single intervention to reach $4.2 \%$ of the total population of adult smokers in England is a major achievement. This makes Quitline a very promising model for public health intervention programs.

(Tobacco Control 2000;9:148-154)

Keywords: telephone helpline; smoking cessation

Although the health benefits of giving up smoking are well established, most smokers find it very difficult to quit. ${ }^{1}$ Surveys conducted by the Health Education Authority in England between 1994 and 1997 show that more than half of smokers said they wanted to quit smoking (survey of knowledge, attitudes and behaviour 1994-1997, unpublished data). During this same period less than $2 \%$ of all adults per year had managed to quit within the last 12 months.

The UK government recently set a target to "reduce adult smoking in all social classes so that the overall rate falls from $28 \%$ to $24 \%$ or less by the year 2010 ; with a fall to $26 \%$ by the year 2005. In terms of today's population this would mean 1.5 million fewer smokers in England". ${ }^{2}$ This is a challenging target because the gradual decline in the prevalence of cigarette smoking which has been observed since the late 1940 s has stopped. ${ }^{13}$ In order to meet the target, interventions with proven effectiveness must be identified. Ideally such interventions should have potential for reaching the maximum number of smokers.

According to a survey of smokers conducted in 1996, over half who had tried to quit in the previous year had used willpower alone. ${ }^{4}$ Other methods tried included nicotine replacement therapy (NRT) (25\%) and health professional advice $(9 \%)$. The least popular approach was smokers' clinics which was tried by only $1 \%$ of those attempting to stop smoking in the previous year. NRT, health professional advice, and smokers' clinics have all been shown to be efficacious. ${ }^{5}$ For example, clinical trials of prescription NRT have shown that it can double a smoker's chance of quitting. ${ }^{5}$ From the survey of smokers it would appear that very few use the methods with proven efficacy. The low use of such approaches may reflect their low accessibility, particularly in terms of cost and convenience. ${ }^{467}$

The telephone helpline offers an intervention with potential for widespread use which is also easily accessible. Several studies have shown that brief telephone counselling may enhance the short and long term cessation rates associated with self help materials. ${ }^{8-13}$ For example, Ossip-Klein and colleagues evaluated the impact of a telephone helpline comprising recorded messages and counsellors as an adjunct to a self-help manual and tape. ${ }^{11} \mathrm{At}$ one year, $11.7 \%$ of the smokers in the helpline group had quit for 48 hours or more compared with $8.1 \%$ of those who received the manual and tape. Similarly, Orleans and colleagues found significantly higher quit rates for those who received telephone counselling (23\%) compared with the control group (18.2\%). ${ }^{12}$ In a study of callers to a Scottish helpline, $23.6 \%$ of smokers reported being abstinent at one 
year. The respondents in this study were prompted to call the helpline by a hard hitting TV advertising campaign. ${ }^{8}$ Lichtenstein and colleagues recently reviewed the evidence on helplines and concluded that reactive helplines "appear to be efficacious and useful as a public intervention for large populations". ${ }^{14}$ In a meta-analysis of studies of proactive helplines Lichenstein and colleagues estimated pooled odds ratios of 1.34 (95\% confidence intervals (CI) 1.19 to 1.51 ) and 1.2 (95\% CI 1.06 to 1.37) for quitting in the short and long term, respectively. ${ }^{14}$

Since 1994 the Health Education Authority for England has run a national mass media campaign aimed at encouraging smokers to quit. As part of this campaign smokers are encouraged through TV and radio advertising to call Quitline, a free telephone helpline for smokers who want to stop smoking and others who would like to help smokers to quit. The helpline is staffed by trained counsellors who offer one-to-one telephone information, advice, and counselling. Callers can also receive an information pack through the post containing information on a variety of smoking related topics such as the risks of smoking and advice on how to quit.

The counselling service currently has the capacity to operate a maximum of 20 lines. In the event of all counselling lines being engaged callers are automatically transferred to a bureau comprising at least 600 additional lines that can be accessed simultaneously. The bureau enables callers to leave their name and address should they want an information pack and invites them to phone back later when the lines are less busy if they want to speak to a counsellor. Should the capacity of the bureau be exceeded, callers are transferred to a messagelink with an additional 50 lines which, like the bureau, allows callers to leave their names and addresses.

The Quitline counsellors adopt a nondirective approach to smoking cessation. Callers are encouraged to learn from their own experience, to identify reasons for previous failed attempts (if they have made any), and to identify ways in which they might overcome these problems in the future. They are also asked to think about situations in which they might find it hard not to smoke and consider ways of coping with these situations. Callers are assessed on their smoking history, quitting history, and confidence about the impending quit attempt.

The advertising campaign comprised television and radio advertisements and was supported by advertorials (adverts that look like editorial) in women's magazines. The television advertisements were targeted at young smokers (aged 16-24 years) and aimed to challenge their reasons for smoking and provide them with reasons to quit. In contrast to previous campaigns, the TV adverts adopted a hard hitting testimonial approach. The radio and magazine adverts were aimed at a slightly wider audience and were intended to provide support and encouragement to those who want to quit. All adverts included the freephone Quitline number.

The purpose of the present paper is to report the extent of short and long term changes in smoking behaviour among those who called the helpline during the Health Education Authority's three month TV and radio advertising campaign. Additional objectives of the study not reported here include an assessment of whether caller profiles and call volumes are influenced by TV advertising campaigns promoting the service, and an assessment of callers perceptions of the service. $^{15}$

\section{Method}

The research comprised three main stages. The first involved an analysis of caller profiles from log sheets completed by Quitline counsellors. The second and third stages involved a series of telephone recall interviews with a sample of callers conducted two months and one year after their initial call to the helpline. The recall interviews were carried out by Consumer Focus, an independent research company.

\section{LOG SHEET SAMPLE}

Information on sex, age, smoking related behaviour, reason for calling, nature of call (first or repeat), whether calling for self or on behalf of someone else, and source of obtaining the helpline number was recorded by the counsellor for each interactive call. Data on social class was not collected at the initial call because it is both time consuming to collect and requires trained interviewers to ensure accurate coding. Moreover, since initial calls are made by smokers seeking help, counsellors argue that it is too disruptive to collect such sensitive information at the first call.

Between 26 December 1997 and 31 March 1998, $32197 \mathrm{log}$ sheets were completed. Of these, $25 \%$ were hoax/silent calls and $20 \%$ had three or more of the 14 questions on the log sheet uncompleted. These were excluded from further analyses. Of the remaining $18873 \mathrm{log}$ sheets 3019 (around 1/6) were randomly selected in proportion to the total number of calls received each day for analysis.

RECALL SAMPLES

At the end of the call, the counsellor invited the caller to leave their telephone number if they were happy to be contacted in a couple of months by an independent research agency who wanted to see how they were progressing. Of the $18873 \log$ sheets at baseline, $6038 \mathrm{had}$ telephone numbers. From these 905 (around 1/7) were selected for the two month recall survey. The sample was randomly selected in proportion to the total number of calls received on a week by week basis.

The one year recall study was undertaken when additional funds were made available about 11 months after completion of the baseline study. Within the budget available, an attempt was made to re-contact 750 of the 905 respondents who had been recalled at two months. In the event only 473 re-contact inter- 
Table 1 Profile of adults, smokers and recent ex-smokers by sex, age, social class and presence of children in household

\begin{tabular}{|c|c|c|c|c|c|c|}
\hline & \multicolumn{2}{|c|}{ Adult survey* } & \multicolumn{4}{|c|}{ Callers to Quitline } \\
\hline & Smokers & $95 \% C I$ & Baseline & $95 \% C I$ & $\begin{array}{l}\text { Total at one } \\
\text { year }\end{array}$ & $95 \% C I$ \\
\hline Unweighted base & $4197(2$ & & 3018 & & 730 & \\
\hline \multicolumn{7}{|l|}{ Sex } \\
\hline Male & $50 \%$ & 48.49 to 51.51 & $40 \%$ & 38.25 to 41.75 & $28 \%$ & 24.74 to 31.26 \\
\hline Female & $49 \%$ & 47.49 to 50.51 & $60 \%$ & 58.25 to 61.75 & $72 \%$ & 68.74 to 75.26 \\
\hline \multicolumn{7}{|l|}{ Age (years) } \\
\hline$<16$ & N/A & - & $15 \%$ & 13.73 to 16.27 & - & - \\
\hline $16-24$ & $19 \%$ & 17.81 to 20.19 & $18 \%$ & 16.63 to 19.37 & $7 \%$ & 5.15 to 8.85 \\
\hline $25-34$ & $24 \%$ & 22.71 to 25.29 & $31 \%$ & 29.35 to 32.65 & $32 \%$ & 28.62 to 35.38 \\
\hline $35-44$ & $18 \%$ & 16.84 to 19.16 & $20 \%$ & 18.57 to 21.43 & $29 \%$ & 25.71 to 32.29 \\
\hline $45+$ & $38 \%$ & 36.53 to 39.47 & $17 \%$ & 15.66 to 18.34 & $31 \%$ & 27.64 to 34.36 \\
\hline \multicolumn{7}{|l|}{ Social class } \\
\hline Non-manual (ABC1) & $39 \%$ & 37.52 to 40.48 & N/A & - & $34 \%$ & 30.56 to 37.44 \\
\hline Manual/unemployed (C2DE) & $61 \%$ & 59.52 to 62.48 & N/A & - & $63 \%$ & 59.50 to 66.50 \\
\hline \multicolumn{7}{|l|}{ Children in household } \\
\hline Any under 16 years & $36 \%$ & 34.55 to 37.45 & $44 \%$ & 42.23 to 45.77 & $50 \%$ & 46.37 to 53.63 \\
\hline None under 16 years & $64 \%$ & 62.55 to 65.45 & $56 \%$ & 54.23 to 57.77 & $50 \%$ & 46.37 to 53.63 \\
\hline \multicolumn{7}{|l|}{ Consumption } \\
\hline Light $1-9$ a day & $21 \%$ & 19.77 to 22.23 & $11 \%$ & 9.88 to 12.12 & $15 \%$ & 12.41 to 17.59 \\
\hline Medium $10-19$ a day & $42 \%$ & 40.51 to 43.49 & $31 \%$ & 29.35 to 32.65 & $40 \%$ & 36.45 to 43.55 \\
\hline Heavy $20+$ a day & $36 \%$ & 34.55 to 37.45 & $58 \%$ & 56.24 to 59.76 & $44 \%$ & 40.40 to 47.60 \\
\hline \multicolumn{7}{|l|}{ Length of time been a smoker } \\
\hline 2 years or less & N/A & - & $14 \%$ & 12.76 to 15.24 & $2 \%$ & 0.98 to 3.02 \\
\hline $3-5$ years & N/A & - & $13 \%$ & 11.8 to 14.2 & $1 \%$ & 0.28 to 1.72 \\
\hline Over 5 years up to 10 & N/A & - & $19 \%$ & 17.6 to 20.4 & $14 \%$ & 11.48 to 16.52 \\
\hline Over 10 years up to 20 & N/A & - & $27 \%$ & 25.42 to 28.58 & $32 \%$ & 28.62 to 35.38 \\
\hline Over 20 years & N/A & - & $26 \%$ & 24.44 to 27.56 & $45 \%$ & 41.39 to 48.61 \\
\hline Average & & & 14.0 yea & & 20.7 years & \\
\hline
\end{tabular}

Missing values excluded from base; ^Health Education Authority’s adult survey (unpublished).

views were achieved. A fresh sample $(\mathrm{n}=951)$ was randomly drawn from the 5133 baseline log sheets with telephone numbers that had not been used for the two month recall study. This provided an additional 257 respondents. Thus a total of 730 respondents were interviewed one year after their initial call to Quitline.

The main reasons for non-contact at one year among the two month recall sample (base $\mathrm{n}=905)$ were refusal to participate $(8 \%)$, number unobtainable $(17 \%)$, and wrong number/contact moved ( $8 \%)$. Among the fresh sample (base $n=951$ ) the main reasons were no reply/answerphone $(27 \%)$, number unobtainable $(22 \%)$, and number inadequate $(11 \%)$. Only $2 \%$ of the fresh sample refused to be interviewed as part of the one year follow up.

At both two months and one year information was collected on current smoking status, past smoking history, and some demographic details such as social class, marital status, and housing tenure. Social classes $\mathrm{ABC} 1$ include professional, managerial, clerical, and administrative grades; C2DEs include skilled manual and unskilled manual and those on state benefits. Questions were also included on perceptions of the service, other sources of help, reasons for relapse, and perceived likelihood of smoking in three months. The total number of questions amounted to 33 ; some questions had several parts.

POPULATION SAMPLE

Data on the sociodemographic profile of smokers in England are provided by the Health Education Authority's annual surveys of adults aged 16 and over carried out between 1994 and 1997. Each survey adopts a random prob- ability sampling technique providing information on 8500 households and 17000 adults.

\section{Results}

CHARACTERISTICS OF CALLERS

Table 1 shows the sociodemographic profile for a representative sample of adult smokers in England and callers to the Quitline. Compared with all smokers, callers were more likely to be women, to be in the age groups 25-34 or 35-44 years, to come from households with children under the age of 16 years, and to be heavy smokers (smoke 20 or more cigarettes a day). At one year the social class profile of callers to the helpline reflected the social class profile of all adult smokers; $63 \%$ of the sample were of manual occupations or unemployed compared with $61 \%$ of the adult smoker population.

Some differences emerged between the caller profiles at baseline and one year recall. Compared with callers at baseline, women, those aged 35 and over, and those with moderate consumption levels (10-19 cigarettes a day) were overrepresented in the one year recall sample. The one year recall sample also included more long term smokers.

CHANGE IN SMOKING STATUS

Among smokers at baseline, $23 \%$ reported having stopped smoking at the two month follow up while $22 \%$ reported having stopped at one year. A further $35 \%$ of smokers reported that they had reduced their consumption at the two month recall compared with $29 \%$ at the one year recall. Among ex-smokers, 57\% reported still not smoking at two months while $41 \%$ reported still not smoking at one year (table 2). Of those who had resumed smoking at one year $28 \%$ were smoking less than they had been initially. 
Table 2 Smoking behaviour change at two months and one year follow up

\begin{tabular}{|c|c|c|c|c|c|c|}
\hline & \multicolumn{3}{|c|}{2 months } & \multicolumn{3}{|c|}{1 year } \\
\hline & $\%$ & $95 \% C I$ & $n$ & $\%$ & $95 \% C I$ & $n$ \\
\hline Current smokers at initial call & & & 664 & & & 521 \\
\hline Stopped smoking & 23 & 19.8 to 25.6 & 156 & 22 & 18.4 to 25.6 & 114 \\
\hline Switched to low tar brand & 6 & 4.2 to 7.8 & 38 & * & & 1 \\
\hline Reduced consumption & 35 & 31.4 to 38.6 & 235 & 29 & 25.1 to 32.9 & 151 \\
\hline Same consumption & 30 & 26.5 to 33.5 & 202 & 39 & 34.8 to 43.2 & 201 \\
\hline Increased consumption & 5 & 3.3 to 6.7 & 33 & 10 & 7.4 to 12.6 & 54 \\
\hline Ex-smokers at initial call & & & 241 & & & 209 \\
\hline Still not smoking & 57 & 50.7 to 63.3 & 138 & 41 & 34.3 to 47.7 & 86 \\
\hline Started again & 43 & 36.7 to 49.3 & 103 & 59 & 52.3 to 65.7 & 123 \\
\hline
\end{tabular}

^Percentage value close to zero (much less than $1 \%$ ).

To estimate conservatively the impact of the helpline it is assumed: first, that all those who refuse to take part in the one year follow up are smokers at one year; and second, that $20 \%$ of all those who report not smoking at one year fail biochemical validation. ${ }^{11}$ Of those who refused to participate in the one year recall 61 were smokers at baseline and 28 were ex-smokers at baseline. The adjustments yield a cessation rate of $15.6 \%$ (95\% CI $12.7 \%$ to $18.5 \%)$ at one year among callers who were smokers at baseline and 29\% (95\% CI 23.2\% to $34.8 \%$ ) among ex-smokers at baseline.

Of those not smoking at the one year recall stage, $31 \%$ had not smoked since their initial call and a further $30 \%$ had not smoked for over nine months of that time. Of the group who had smoked since their initial call but were not smoking at one year the average number of quit attempts was 2.0 (61\% giving up just once and $7 \%$ over four times).

Of those smoking at one year, $67 \%$ reported having stopped at some point over the past year. The vast majority ( $97 \%$ ) of those making a quit attempt had been able to give up for over 24 hours on at least one occasion, with the average period of the last cessation attempt being around 22 weeks. A total of 3\% claimed not to have smoked for over nine months of that time, and $41 \%$ claimed to have stopped for up to a month. Among those quitting at all the average number of quit attempts was 2.2 (51\% had tried once and $10 \%$ over four times).
The average length of time non-smokers at one year claimed to have not been smoking since their initial call was 39.6 weeks compared to 6.9 weeks for those who were smoking at one year recall.

Looking in more detail at those who were not smoking at one year, among those who were smokers at their initial call $21 \%$ had not smoked since that call, a further $34 \%$ had not smoked for over nine months and $10 \%$ claimed to have stopped for up to a month. Among ex-smokers initially $43 \%$ had not smoked since their initial call, $24 \%$ had not smoked for over nine months, and $6 \%$ claimed to have stopped for up to a month.

Table 3 shows some of the characteristics associated with smoking behaviour changes among callers who were smokers at the initial call. The variables included in this table were predetermined by the published literature on factors predictive of smoking cessation. In this study an increase in the likelihood of quitting appeared to be associated with an increase in age and a decrease in consumption level.

Among ex-smokers initially, the main characteristics associated with not smoking at one year were social classes $\mathrm{ABC} 1$, light smokers, and being male.

The behaviour change reported at one year appeared to be influenced by whether the caller received a two month recall interview. Thus among smokers at baseline, $24 \%$ of those who received the two month recall reported not smoking at one year compared with $18 \%$ who had not received the two month recall $\left(\chi^{2}=3.123\right.$, narrowly missed significance at $\mathrm{p}<0.05)$. Among ex-smokers at baseline, the difference between those who did and those who did not receive a two month recall was not significant ( $43 \%$ and $38 \%$, respectively) but the base was very small. A similar effect was also observed for length of quit attempt, number of quit attempts, and confidence in remaining a non-smoker. Thus, among those recalled at two months, the average length of a quit attempt was 17.5 weeks compared with 13 weeks for those not recalled. The average number of quit attempts was 2.3 for those recalled at two months and 1.5 for those not

Table 3 Changes in smoking behaviour by sociodemographic variables at one year follow up

\begin{tabular}{|c|c|c|c|c|c|c|c|}
\hline & Base (n) & $\begin{array}{l}\text { Stopped } \\
\text { smoking (\%) }\end{array}$ & $95 \% C I$ & $\begin{array}{l}\text { Reduced } \\
\text { consumption } \\
(\%)\end{array}$ & $95 \% C I$ & $\begin{array}{l}\text { Same/increased } \\
\text { consumption (\%) }\end{array}$ & $95 \% C I$ \\
\hline \multicolumn{8}{|l|}{ Sex } \\
\hline Male & 154 & 21 & 13.52 to 28.48 & 32 & 24.56 to 39.44 & 47 & 40.87 to 53.13 \\
\hline Female & 367 & 22 & 14.40 to 29.60 & 28 & 20.84 to 35.16 & 50 & 43.86 to 56.14 \\
\hline \multicolumn{8}{|l|}{ Age (years) } \\
\hline $16-24$ & 42 & 12 & 6.03 to 17.97 & 29 & 21.76 to 36.24 & 60 & 53.99 to 66.01 \\
\hline $25-34$ & 165 & 20 & 12.66 to 27.34 & 28 & 20.84 to 35.16 & 52 & 45.87 to 58.13 \\
\hline $35-44$ & 147 & 23 & 15.27 to 30.73 & 32 & 24.56 to 39.44 & 46 & 39.88 to 52.12 \\
\hline $45+$ & 167 & 25 & 17.05 to 32.95 & 27 & 19.92 to 34.08 & 47 & 43.86 to 56.14 \\
\hline \multicolumn{8}{|l|}{ Social class } \\
\hline Non-manual (ABC1) & 174 & 25 & 17.05 to 32.95 & 29 & 21.76 to 36.24 & 46 & 39.88 to 52.12 \\
\hline Manual/unemployed (C2DE) & 328 & 21 & 13.52 to 28.48 & 29 & 21.76 to 36.24 & 50 & 43.86 to 56.14 \\
\hline \multicolumn{8}{|l|}{ Consumption } \\
\hline Light $<10$ & 33 & 36 & 27.19 to 44.81 & 45 & 37.06 to 52.94 & 18 & 13.28 to 22.72 \\
\hline Medium 10-19 & 144 & 28 & 19.76 to 36.24 & 29 & 21.76 to 36.24 & 43 & 36.92 to 49.08 \\
\hline Heavy $20+$ & 329 & 18 & 10.95 to 25.05 & 27 & 19.92 to 34.08 & 55 & 48.89 to 61.11 \\
\hline \multicolumn{8}{|l|}{ Presence of children } \\
\hline Any under 16 years & 257 & 19 & 11.80 to 26.20 & 28 & 20.84 to 35.16 & 53 & 46.87 to 59.13 \\
\hline None under 16 years & 264 & 25 & 17.05 to 32.95 & 30 & 22.69 to 37.31 & 45 & 38.89 to 51.11 \\
\hline Total & 521 & $22 \%(114)$ & & $29 \%(151)$ & & $49 \%(255)$ & \\
\hline
\end{tabular}

Base: All current smokers at initial call (521) 
recalled. Similarly, callers who received the two month recall were more confident about remaining non-smokers than callers who had not received the call back $(66 \%$ and $50 \%$, respectively).

Among those not smoking at one year, levels of confidence in remaining a non-smoker were similar to those reported at two months, with $61 \%$ reporting that they felt very confident. However, motivation to stop smoking altogether among callers who were smoking at one year was somewhat lower than that reported at the two month stage $(68 \%$ want to stop very much indeed at two months compared with $57 \%$ at one year). Not surprisingly, a major difference was observed between those smoking and not smoking at one year in terms of their expectation to be smoking in three months' time $(61 \%$ of smokers felt they would compared with $2 \%$ of those not smoking).

Currently, Quitline receives around 500000 calls a year, of which just over half (268 626) are transferred to counsellors. Of these counselling calls, $71.4 \%$ are received during the three months of the advertising campaign. During this period $93 \%$ of callers are phoning for themselves, of whom $73 \%$ are smokers and $27 \%$ are ex-smokers at their initial call. ${ }^{15}$ Applying the unadjusted figure for stopping smoking at one year to the total number of smokers calling the service for themselves and who speak to a counsellor yields a total of 40121 (33 556-46 614) ex-smokers at one year. The figure for ex-smokers who stay stopped is 27655 (23 136-32 175). When adjusted for refusals and an estimated $20 \%$ failed validation, the conservative estimate for smokers who stop at one year is 28450 (23 161-33 738) and for ex-smokers who stay stopped is 19561 (15 649-23 473).

\section{Discussion}

The results indicate that the Health Education Authority's advertising campaign has been extremely successful in generating calls to Quitline and thus encouraging activity directed towards cessation. More than two fifths of all the calls made to Quitline in one year were received during the three month advertising campaign, and of these more than four out of five were answered by counsellors. With an annual rate of half a million callers, $93 \%$ of whom are calling for themselves, the Quitline is currently reaching more than $4 \%$ of the total population of adult smokers in England, an impressive achievement for a single intervention. Given the diverse backgrounds of the callers these data provide strong support for the feasibility and potential of the Quitline as a model for public health intervention programs.

The Quitline was first advertised as part of a national anti-smoking campaign in England in December 1994. In the present study around $60 \%$ of callers claimed advertising as the source of Quitline awareness. The content of the advertising (for example, supportive or hardhitting) and the advertising mix (for example, television, or television, radio and magazine) appeared not to have influenced call volumes. Compared with previous campaigns overall call volumes have remained more or less the same despite substantial changes to the content and mix of advertising. The constant media spend across different advertising mixes and changes to content may explain this. ${ }^{15} \mathrm{~A}$ crucial factor in achieving the reach observed in this study appears to be the advertising of a freephone number. When Quitline was relaunched with a freephone number in November 1995, call volumes increased nearly nine fold. ${ }^{15}$ The use of a freephone number may also be an important factor in the diverse reach of the Quitline.

Compared with the population of adult smokers in England, callers were more likely to be women, older, more heavily addicted, and have children under the age of 16 years living in the household. The social class distribution of callers to the Quitline reflected the social class distribution of smoking in the population, with nearly two thirds of callers being in manual occupations or unemployed. The profile of callers suggests that the service is successful in attracting some of the groups highlighted in the UK government's recent White Paper on tobacco, "Smoking kills". Given that one fifth of the smokers who called Quitline who were in manual occupations or unemployed reported having stopped at one year, it seems likely that such a service can make a major contribution to achieving smoking reductions among these priority groups.

Currently, $54 \%$ of callers are transferred to counsellors with an associated success rate of $15.6 \%$ (adjusted estimate) among smokers and $29 \%$ among ex-smokers (adjusted estimate). A fourfold increase in calls to counsellors from smokers and ex-smokers (from 3.1\% to $12.4 \%$ ) would mean that the UK government's target to reduce adult smoking to $26 \%$ by the year 2005 could be reached sooner, by the year 2002. This assumes a similar success rate could be achieved with all potential callers to the Quitline. This assumption could prove invalid if the self selected nature of the Quitline callers means that they differ from smokers in the general population in ways that affect success in smoking cessation. Alternatively, the findings might be further improved by efforts to recruit those more likely to succeed in quitting, such as less addicted smokers and those with a shorter history of smoking. As noted above, the profile of callers at one year appears, if anything, to biased away from achieving successful quitting. Additional improvements may also be observed if those who phoned the service and received an information pack, but did not get the opportunity to speak to a counsellor, also stop smoking. Separate studies would be needed to explore these issues. Research would also be needed to determine whether similar rates could be obtained with smokers who phone during periods without paid advertising. The cessation rates reported in this study were obtained with callers who phoned during the Health Education Authority's advertising campaign.

The lack of an appropriate comparison group limits the conclusions that can be drawn 
about the efficacy of the helpline. Nevertheless, the cessation rate in this study is very similar to that reported by Platt and colleagues ${ }^{8}$ and Borland and Hill. ${ }^{13}$ It also compares very favourably with estimates of cessation rates obtained in the absence of interventions, ${ }^{16}{ }^{17}$ In a study by Baillie and colleagues a cessation rate of $7.33 \%$ was observed without any apparent intervention. Even the most cautious estimate in the present study $(15.6 \%)$ is double that reported by Baillie and colleagues. ${ }^{16}$

Lack of biochemical validation is another concern. Several studies have documented that self reported smoking status leads to an overestimate of successful quit attempts.. ${ }^{911}{ }^{12}$ However, when adjusted for an estimated deception rate of $20 \%$ and refusals the present cessation rate is still comparable with studies that incorporated both control groups and biochemical validation. ${ }^{9}{ }^{11} 12$

Another consideration is the bias that may have resulted from attrition. Compared with baseline callers, those followed up at one year were more likely to be women, aged 35 and over and smokers with light $(<10$ cigarettes a day) or moderate cigarette consumption (10-19 cigarettes a day). Various factors have been identified with successful quitting such as being a lighter smoker and being older (aged $40+) .{ }^{11819}$ The evidence concerning sex differences is conflicting. Although sex differences have not always been found, when differences have emerged men have been more successful. ${ }^{7}$ The effect of sex may also be influenced by age. In one study young women were significantly more likely to give up than young men, while middle aged women were less likely to give up than middle aged men. ${ }^{19}$ Given the interaction between age and sex, the change in age and sex profile observed in the present study appears to offer an unlikely explanation of the findings. At one year, $44 \%$ of the sample were women aged $35+$, the group least likely of all to quit. Only $17 \%$ of the sample were men aged $35+$. Changes in consumption are also unlikely to account for the findings because the greatest increase was among moderate smokers from $31 \%$ of the sample at baseline to $40 \%$ at one year. Among light smokers the increase was from $11 \%$ at baseline to $15 \%$ at one year. On balance, the profile of callers at one year appears, if anything, to be biased away from achieving successful quitting.

Information on social class was not available at baseline and so it is not possible to assess any bias attributable to this factor. However, as reported earlier, the social class profile at one year matched that of the adult population of smokers in England. (survey of knowledge, attitudes and behaviour 1994-1997, unpublished data). Two thirds of the callers at one year were from manual and unemployed households. Since successful quitting is associated with higher rather than lower socioeconomic status, ${ }^{20-22}$ social class bias in the Quitline sample appears an unlikely explanation of the present findings.

The results of this study also point to the need to consider reducing prevalence by providing relapse prevention to smokers who have already achieved initial cessation. In the present study $27 \%$ of initial callers were ex-smokers of whom $59 \%$ relapsed at one year. One approach to preventing relapse might be to offer proactive call backs to initial callers since research has shown that the provision of more than one telephone session may be beneficial. $^{910}$ The timing of call backs is arguably best determined by the shape of the relapse curve. ${ }^{23}$ Typically the probability of relapse is much greater in the initial stages than in the later stages of quitting and so smokers' need for help is strongest soon after they attempt to quit. Indeed the relapse curve for smoking cessation indicates that maximum relapse $(60 \%)$ occurs within one week after a quit attempt. ${ }^{23}$ The optimum timing and the number of call backs would need to be tested in a future study. Additionally, future research should include an assessment of the content of counselling, including any relapse prevention component, in order to determine which aspects of the counselling process are important in generating positive smoking behaviour change.

Overall, the results indicate that telephone counselling can produce positive outcomes in terms of smoking cessation. The high accessibility and convenience of the telephone format suggests that this approach to smoking cessation provides a promising addition to the interventions currently available.

I would like to thank Tina Hutton of Consumer Focus for her contribution to this study. Thanks are also due to Steve Crone, Quitline coordinator, and the counsellors at Quit who made this Quitline coordinator, and the counsellors at Quit who made this study possible. Finally, I would like to thank Steve Woodward for his support, ideas, and comments as well as Keith Bolling for research was funded by the Department of Health.

1 Callum C. The UK smoking epidemic: deaths in 1995. London: Health Education Authority, 1998.

2 Anon. Smoking kills: a White Paper on tobacco. London: The Stationery Office, 1998.

3 Thomas M, Walker A, Wilmot A, Bennett N. Living in Britain: results from the 1996 general household survey. London: Office for National Statistics, The Stationery Office, 1998. 4 Evans N, Owen L, McNeill A, et al. Smoking and the consumer: perceptions of stop smoking products and services. A survey commissioned by the Health Education Authority for No Smoking Day, 1999. London: Health Education Authority.

5 Raw M, McNeill A, West R. Smoking cessation guidelines for health professionals: a guide to effective smoking cessation interventions for the health care system. Thorax 1998;53 (suppl 5).

6 Hines D. Young smokers' attitudes about methods for quitting smoking: barriers and benefits to using assisted methods. Addict Behav 1996;21:531-5.

7 Ward KD, Klesges RC, Zbikowski SM, Bliss RE, Garvey AJ. Gender differences in the outcome of an unaided smoking cessation attempt. Addict Behav 1997;22:521-33.

8 Platt S, Tannahill A, Watson J, Fraser E. Effectiveness of antismoking telephone helpline: follow up survey. BMF 1997;314:1371-5.

9 Zhu SH, Stretch V, Balabanis M, Rosbrook B, Sadler G, Pierce J. Telephone counselling for smoking cessation: effects of single-session and multiple-session interventions. J Consult Clin Psychol 1996;64:202-11.

10 Britt J, Curry SJ, McBride C, Grothaus L, Louie D. Implementation and acceptance of outreach telephone counselling for smoking cessation with nonvolunteer smokers. Health Educ Q 1994;21:55-68.

11 Ossip-Klein DJ, Giovino GA, Megahed N, et al. Effects of a smokers' hotline: results of a 10-county self-help trial. $\mathcal{f}$ Consult Clin Psychol 1991;59:325-32.

12 Orleans CT, Schoenbach VJ, Wagner EH, et al. Self-help quit smoking interventions: effects of self-help materials, social support instructions, and telephone counselling. $f$ Consult Clin Psychol 1991;59:439-48.

13 Borland R, Hill D. Two-month follow-up on callers to a telephone quit smoking service. Drug and Alcohol Review 1990;9:211-18.

14 Lichtenstein E, Glasgow RE, Lando HA, Ossip-Klein DJ, Boles SM. Telephone counselling for smoking cessation: rationales and meta-analytic review of evidence. Health Educ Res 1996;11:243-57. 
15 Owen L, Lafferty G. Ouitline: an audit of the national helpline for smokers 1995-1998. London: Health Education Authority, 1999.

16 Baillie AJ, Mattick RP, Hall W. Quitting smoking: estimation by meta-analysis of the rate of unaided smoking cessation. Aust f Public

17 Fiore MC, Thomas NE, Pierce JP, et al. Methods used to quit smoking in the United States: do cessation programs help? $\mathcal{F} A M A$ 1990;263:2760-5.

18 Gourlay SG, Forbes A, Marriner T, Pethica D, McNeill JJ. Prospective study of factors predicting outcome of transdermal nicotine treatment in smoking cessation. $B M \mathcal{f}$ 1994;309:842-6.

19 Jarvis M. Recent trends in smoking and cessation. A report produced for the Health Education Authority. London: Health Education Authority, 1997.
20 Lundberg O, Rosen B, Rosen M. Who stopped smoking? Results from a panel survey of lining conditions in Sweden. Soc Sci Med 1991;32:619-22.

21 Osler M, Prescott E. Psychosocial, behavioural, and health determinants of successful smoking cessation: a longitudinal study of Danish adults. Tobacco Control 1998;7:262-7.

22 Wardle J, Farrell M, Hillsdon M, Jarvis M, Sutton S, Thorogood M. Smoking, drinking, physical activity and screening uptake and health inequalities. In: Gordon D, Shaw $M$, Dorling D Davy Smith G. Inqualities in health: the evidence presented to the independent inquiry into inequalities in health. Bristol: The Policy Press, 1999:213-39.

23 Zhu SH, Pierce JP. A new scheduling method for time limited counselling. Professional Psychology: Research and Practice $1995 ; 26: 624-5$.

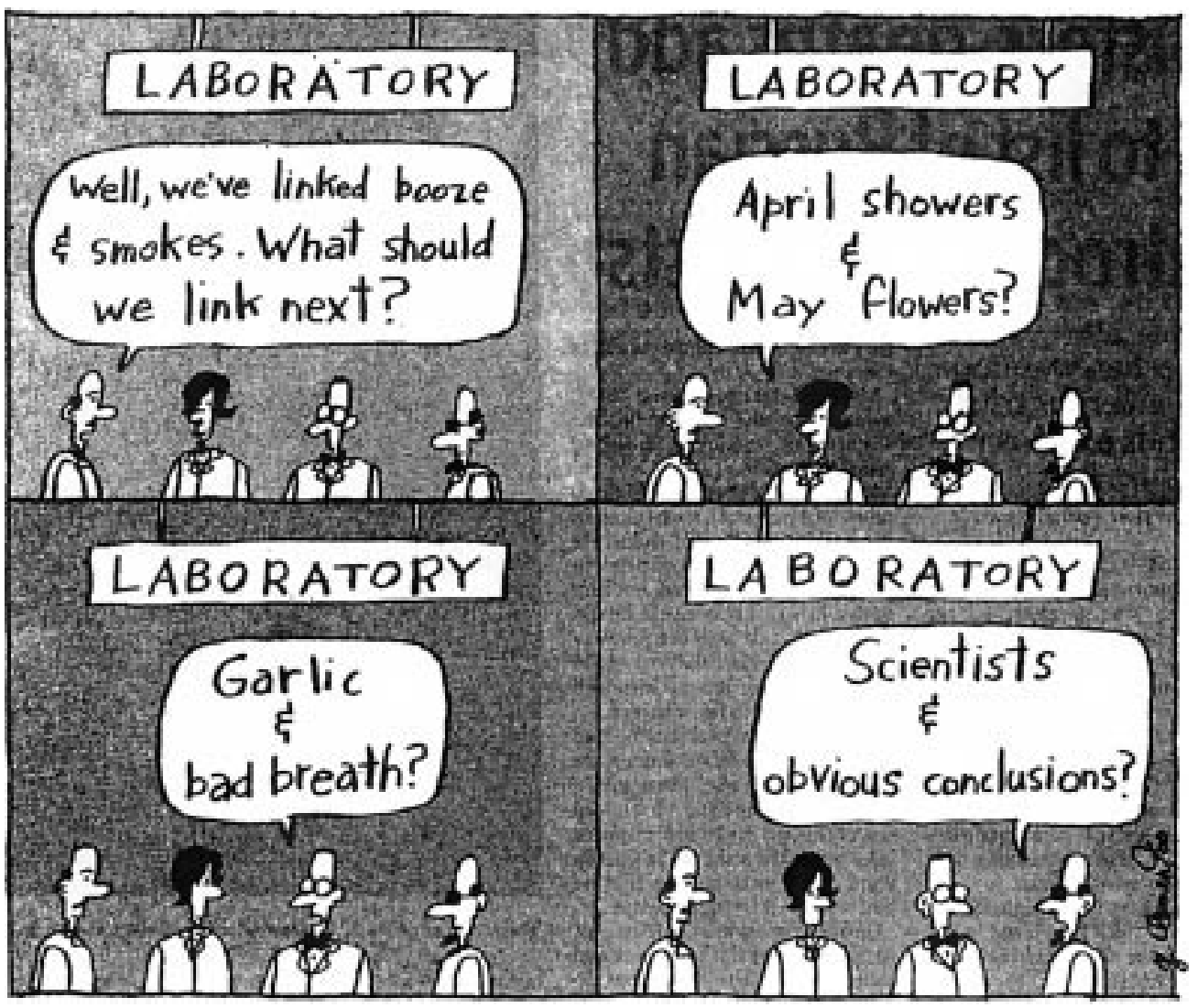

On 17 February 1999, a news item on Adelaide radio announced that "American reseachers will spend the next five years trying to uncover whether teenagers are more likely to get hooked on smoking than adults." Need we say more? 